\title{
Effect of early physician follow-up on mortality and subsequent hospital admissions after emergency care for heart failure: a retrospective cohort study
}

\author{
Clare L. Atzema MD MSc, Peter C. Austin PhD, Bing Yu PhD, Michael J. Schull MD MSc, \\ Cynthia A. Jackevicius PharmD MSc, Noah M. Ivers MD PhD, Paula A. Rochon MD MPH, Douglas S. Lee MD PhD
}

Cite as: CMAJ 2018 December 17;190:E1468-77. doi: 10.1503/cmaj.180786

\begin{abstract}
BACKGROUND: The 1-year mortality rate in patients with heart failure who are discharged from an emergency department is $20 \%$. We sought to determine whether early follow-up after discharge from the emergency department was associated with decreased mortality or subsequent admission to hospital.
\end{abstract}

METHODS: This retrospective cohort study conducted in Ontario, Canada, included adult patients who were discharged from 1 of 163 emergency departments between April 2007 and March 2014 with a primary diagnosis of heart failure. Using a propensity score-matched landmark analysis, we assessed follow-up in relation to mortality and admissions to hospital for cardiovascular conditions.

RESULTS: Of 34519 patients, 16274 (47.1\%) obtained follow-up care within 7 days and 28846 (83.6\%) within 30 days. Compared with follow-up between day 8 and 30 , patients with follow-up care within 7 days had a lower rate of mortality over 1 year (hazard ratio [HR] 0.92; 95\% confidence interval $[\mathrm{Cl}]$ 0.87-0.97), and a reduced rate of admission to hospital over 90 days (HR 0.87, 95\% Cl 0.80-0.94) and 1 year (HR 0.92; 95\% Cl 0.87-0.97); the mortality rate over 90 days in this group trended to a lower rate (HR 0.90, 95\% Cl 0.10-1.00). Follow-up care within 30 days, compared with patients without 30-day follow-up, was associated with a reduction in 1-year mortality (HR 0.89, 95\% Cl 0.82-0.97) but not admission to hospital (HR 1.02, 95\% Cl 0.94-1.10). In this group, there was a trend toward an increase in 90-day admission to hospital (HR 1.14, 95\% Cl 1.00-1.29).

INTERPRETATION: Follow-up care within 7 days of discharge from the emergency department was associated with lower rates of long-term mortality, as well as subsequent hospital admissions, and a trend to lower short-term mortality rates. Timely access to longitudinal care for patients with heart failure who are discharged from the emergency setting should be prioritized.

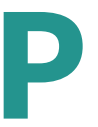

atients with heart failure often experience exacerbations of their disease, ${ }^{1,2}$ when they may seek care in an emergency department. There are over a million visits to the emergency department for heart failure annually in North America, accounting for $3 \%$ of all visits, and they are increasing. ${ }^{3}$ Between $64 \%$ and $84 \%$ of these patients are admitted to hospital in Canada, Europe and the United States. ${ }^{1,3-5}$ In Canada, the direct costs of heart failure are $\$ 2.8$ billion per year. Admissions to hospital constitute most of the expenditures on heart fail$u_{r} e^{6,7}$ and in the current environment of accelerating health care $\operatorname{costs}^{8}$ there is growing preference to choose outpatient over inpatient management where possible. ${ }^{9}$ However, there are limited data on the effect and timing of follow-up care on outcomes after discharge from an emergency department. ${ }^{10,11}$ Physician follow-up within 7 days of discharge from the hospital has been associated with lower 30-day readmissions in patients with heart failure. ${ }^{12}$

In the emergency department, acute symptoms of heart failure are usually treated with diuretics. ${ }^{1,2}$ However, it is long-term disease management, including administration of guideline-directed medical therapy, ${ }^{13,14}$ that likely decreases the risk of death and subsequent admissions to hospital. ${ }^{2,15-18}$ Follow-up care is needed to ensure that guideline-directed medical therapy is instituted and dosages are optimized, and that early evidence of deterioration is addressed. ${ }^{19}$ Emergency physicians recommend follow-up for cardiovascular ambulatory care sensitive conditions within 7 days, ${ }^{20}$ but the optimal timing of physician follow-up is unclear. We sought to determine what the optimal timing of physician followup should be by examining the association between timing of follow-up care and subsequent admissions to hospital and death. 


\section{Methods}

\section{Sources of data}

We identified patients using the Canadian Institutes of Health Information National Ambulatory Care Reporting System (CIHINACRS), an administrative database that contains information on all emergency department visits made in Ontario, Canada. ${ }^{21}$

We linked patients in CIHI-NACRS to other health data sets at our research institute (ICES) using the unique encoded health card number (Appendix 1, part a, available at www.cmaj.ca/ lookup/suppl/doi:10.1503/cmaj.180786/-/DC1). We used neighbourhood income data from Statistics Canada to assign patients to an income quintile based on residential postal code. We defined rural areas using the Statistics Canada definition of areas with less than 10000 persons. $^{22}$

\section{Study population and design}

We included patients aged 18 years and older who made a visit to the emergency department between Apr. 1, 2007, and Mar. 31, 2014, with a primary (first) diagnosis of heart failure. Only the first visit by each patient during the study period was included. We excluded specialty emergency departments (e.g., pediatric) and those not open 24 hours per day, because these are typically lower-acuity, clinic-style sites. We excluded patients with a low-acuity triage score of 4 or 5 on the 5-point emergency department Canadian Triage and Acuity Scale ${ }^{23}$ (e.g., purpose of visit was prescription refill), because they were unlikely to require timely follow-up. We excluded those who were admitted to hospital or died in the emergency department, as well as patients who could not be assigned to a family physician, because they would have different access to follow-up care than patients who had a family physician.

We subsequently analyzed use of guideline-directed medical therapy 1 year after presentation, restricting the cohort to patients who were not already taking guideline-directed medical therapy for heart failure. We excluded patients who were younger than 66 years of age in this analysis because comprehensive medication data are not available in the Ontario Drug Database for this age group, ${ }^{24}$ and we excluded patients who died during the follow-up period.

\section{Outcome measures}

The primary outcome was 1-year all-cause mortality. Secondary outcome measures included 90-day all-cause mortality, and 1-year and 90-day admission to hospital. To avoid counting unrelated admissions to hospital (e.g., renal colic), we limited admissions to hospital to those with a main diagnosis code that was cardiovascular (i.e., International Classification of Diseases and Related Health Problems, 10th revision codes in chapter IX [ICD-10]). We also examined subsequent diagnostic testing and interventions (i.e., echocardiograms, stress testing, catheterizations, revascularizations and implantable cardioverterdefibrillators) and use of guideline-directed medical therapy 1 year after discharge (a new prescription of a guideline-directed medication that was dispensed between day 320 and 410 after discharge). The latter included a medication from any of the following classes: angiotensinconverting-enzyme inhibitors, angiotensin II receptor blockers, $\beta$-blockers (with the exception of sotalol, pindolol and acebutolol) and aldosterone antagonists (spironolactone and eplerenone). ${ }^{2}$

\section{Statistical analysis}

We made the following comparisons: follow-up care within 7 days ("early" care) compared with days 8 through 30; and follow-up care within 1 to 30 days ("basic" care) compared with no 30-day follow-up care. Seven and 30 days were chosen based on follow-up recommendations from emergency physicians and to be consistent with previous work. ${ }^{20,25}$ We decided a priori to define follow-up care as care by physicians who would be expected to assume responsibility for ongoing care of the heart failure (i.e., a family physician, a cardiologist or an internist).

Univariate comparisons were performed with 1-way analysis of variance for mean values, the Kruskal-Wallis test for medians and the $\chi^{2}$ test for proportions.

To avoid immortal-time bias and reverse causality when defining time-based exposure groups, we used a landmark design..$^{25,26}$ In a landmark analysis, the exposure period is defined a priori: we set the landmark at 30 days. Patients who had the outcome (e.g., death) during the exposure period (i.e., before $30 \mathrm{~d}$ ) are excluded. Outcomes are assessed starting at the end of the exposure period (i.e., $30 \mathrm{~d}$ after discharge from the emergency department). Although this avoids the aforementioned biases, it does result in a cohort that consists of healthier patients, as those who had the outcome within the landmark date are excluded.

To adjust for differences in illness severity between groups, we used propensity score methods. ${ }^{27,28}$ We matched on 37 variables, chosen based on our previous work and review of the literature. ${ }^{2,4,10,25,29-31}$ Validated ICD codes and algorithms were used where available. ${ }^{32-38}$ These variables were included in a logistic regression model, and patients were matched 1:1 on the logit of the propensity score using a greedy nearest-neighbour matching algorithm, with a caliper width of 0.2 of the standard deviation of the logit of the propensity score. ${ }^{39,40}$ We assessed the balance between matched groups using standardized differences. ${ }^{41}$

To assess differences in the rate of outcomes between matched groups, we used cause-specific hazards models with follow-upcare type as the sole covariate, treating death as a competing risk for the admission to hospital outcome, and using a robust variance estimator to account for clustering of patients within matched pairs. ${ }^{42}$ Kaplan-Meier curves were fit on matched patients for the mortality outcomes. We repeated the analyses stratifying on patient sex and in patients with no history of heart failure.

To explore potential mediators of differences in outcomes, we compared subsequent diagnostic testing and interventions performed up to 1 year after discharge from the emergency department between the matched follow-up groups. Finally, we performed a logistic regression examining the adjusted association of early follow-up, and follow-up between days 8 and 30, compared with no 30-day follow-up (3-level exposure variable), on use of a new guideline-directed medical therapy medication 1 year after discharge among patients who were not already receiving guideline-directed medical therapy. All analyses were performed with SAS software (version 9.3).

\section{Ethics approval}

This retrospective cohort study was approved by the Research Ethics Board of the Sunnybrook Health Sciences Centre, Toronto, Ontario. 


\section{Results}

Of the 34519 eligible patients with heart failure who were discharged from the emergency department (Figure 1), 16274
(47.1\%) and 28846 (83.6\%) obtained follow-up care within 7 and 30 days of discharge, respectively. Patients without 30-day care, among other differences, were more likely to be in the lowest socioeconomic group and live in a rural area (Table 1). One-third

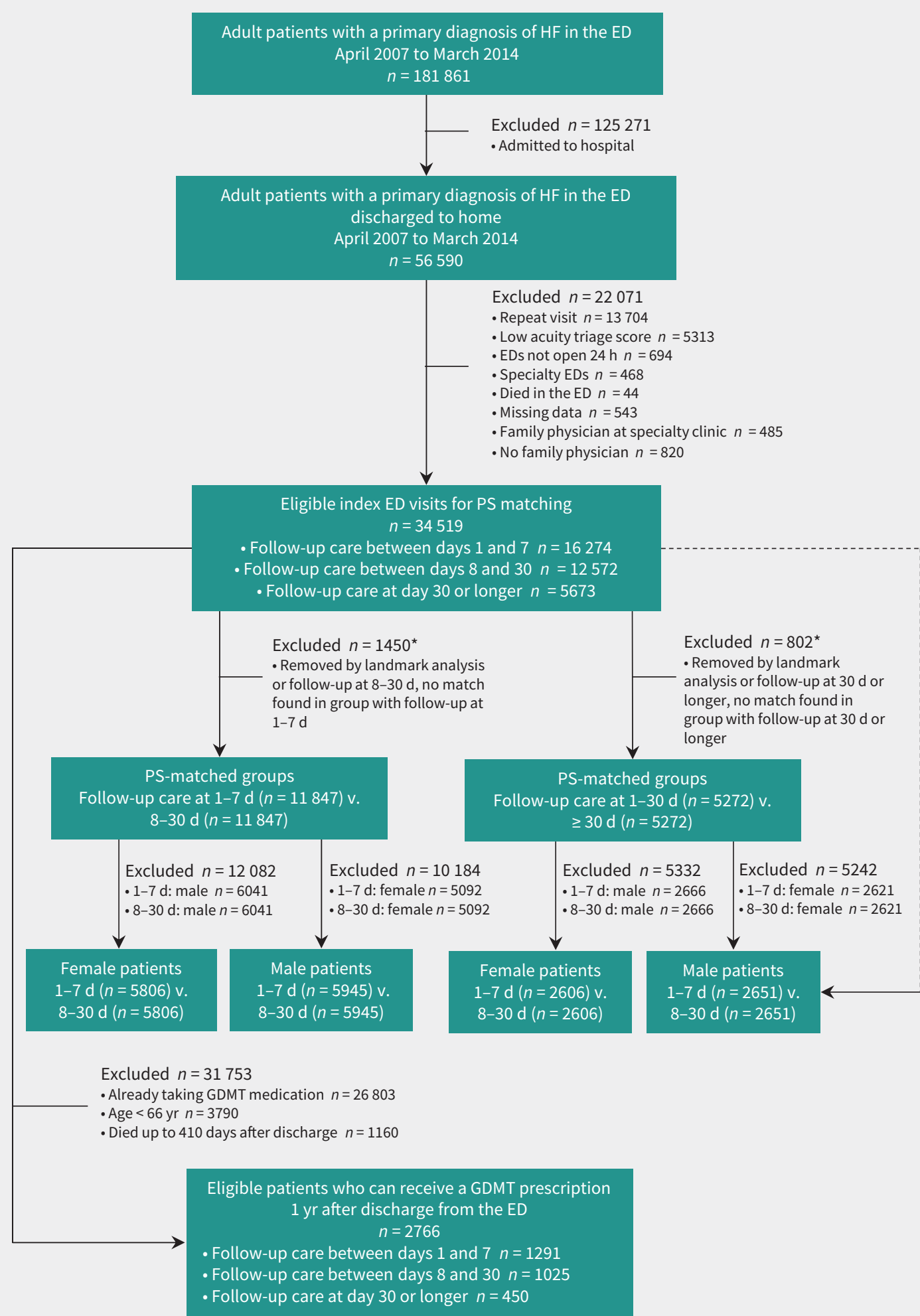

Figure 1: Flow chart for study participants. Note: $\mathrm{ED}=$ emergency department, GDMT = guideline-directed medical therapy, $\mathrm{HF}=$ heart failure, $\mathrm{PS}=$ propensity score. * Met outcome within 30 days (Appendix 1, part b, available at www.cmaj.ca/lookup/suppl/doi:10.1503/cmaj.180786/-/DC1). 
of the cohort had no history of heart failure. Almost one-quarter (24\%) died within 1 year of the visit, with the lowest rate of mortality among those with early follow-up (Table 2).

Of the 12253 patients with follow-up between days 8 and 30 who remained after application of the landmark (Appendix 1, part b), $96.7 \%$ were successfully propensity-score matched to a patient with early follow-up. For the 30-day care analysis, all 5272 patients without 30-day follow-up who remained after application of the landmark were successfully matched to a patient with basic follow-up care. Absolute standardized differences were less than $10 \%$ in both comparator groups (Appen$\operatorname{dix} 1$, parts $c$ and d).

\section{Mortality}

Compared with obtaining follow-up between days 8 and 30, matched patients with early follow-up had a lower rate of death

Table 1 (part 1of 2): Patient characteristics at index emergency department visit for heart failure, by timing of follow-up care

\begin{tabular}{|c|c|c|c|c|c|}
\hline \multirow[b]{2}{*}{ Characteristic } & \multirow{2}{*}{$\begin{array}{c}\text { Total no. of } \\
\text { patients }(\%)^{\star} \\
n=34519\end{array}$} & \multicolumn{3}{|c|}{ No. (\%) of patients with follow-up care* } & \multirow[b]{2}{*}{$p$ value } \\
\hline & & $\begin{array}{c}\text { At } 1-7 \text { d } \\
n=16274\end{array}$ & $\begin{array}{l}\text { At } 8-30 d \\
n=12572\end{array}$ & $\begin{array}{c}\text { No } 30-d \text { care } \\
n=5673\end{array}$ & \\
\hline \multicolumn{6}{|l|}{ Demographic } \\
\hline \multicolumn{6}{|l|}{ Age, yr } \\
\hline Mean $(95 \% \mathrm{Cl})$ & $76.4(76.3-76.5)$ & $76.5(76.4-76.7)$ & $76.6(76.3-76.8)$ & $75.6(75.3-75.9)$ & $<0.001$ \\
\hline Median (IQR) & $78.0(69.0-85.0)$ & $78.0(70.0-85.0)$ & $79.0(70.0-85.0)$ & $78.0(68.0-85.0)$ & 0.003 \\
\hline Sex, female & $16888(48.9)$ & $7840(48.2)$ & $6251(49.7)$ & $2797(49.3)$ & 0.03 \\
\hline \multicolumn{6}{|l|}{ Income quintile (5 is the highest) } \\
\hline 1 & $8065(23.4)$ & $3572(21.9)$ & $3015(24.0)$ & $1478(26.1)$ & $<0.001$ \\
\hline 2 & $7582(22.0)$ & $3586(22.0)$ & $2750(21.9)$ & $1246(22.0)$ & \\
\hline 3 & $6804(19.7)$ & $3266(20.1)$ & $2446(19.5)$ & $1092(19.2)$ & \\
\hline 4 & $6437(18.6)$ & 3069 (18.9) & $2354(18.7)$ & $1014(17.9)$ & \\
\hline 5 & $5631(16.3)$ & $2781(17.1)$ & $2007(16.0)$ & $843(14.9)$ & \\
\hline Rural residence & $5496(15.9)$ & $2299(14.1)$ & $2111(16.8)$ & $1086(19.1)$ & $<0.001$ \\
\hline Living in a long-term care facility & $2100(6.1)$ & $853(5.2)$ & $964(7.7)$ & $283(5.0)$ & $<0.001$ \\
\hline \multicolumn{6}{|l|}{ Medical history } \\
\hline Heart failure & $23246(67.3)$ & $10772(66.2)$ & $8607(68.5)$ & $3867(68.2)$ & $<0.001$ \\
\hline Hypertension & $30310(87.8)$ & $14375(88.3)$ & $10999(87.5)$ & $4936(87.0)$ & 0.01 \\
\hline Atrial fibrillation & $17618(51.0)$ & $8754(53.8)$ & $6452(51.3)$ & $2412(42.5)$ & $<0.001$ \\
\hline Acute myocardial infarction & $17804(51.6)$ & $8473(52.1)$ & $6560(52.2)$ & $2771(48.8)$ & $<0.001$ \\
\hline Coronary artery disease & $15320(44.4)$ & $7144(43.9)$ & $5687(45.2)$ & 2489 (43.9) & 0.05 \\
\hline CABG & 4098 (11.9) & $1946(12.0)$ & $1573(12.5)$ & $579(10.2)$ & $<0.001$ \\
\hline ICD/PPM & $2632(7.6)$ & $1284(7.9)$ & $979(7.8)$ & $369(6.5)$ & 0.002 \\
\hline Stroke & 4066 (11.8) & $1907(11.7)$ & $1475(11.7)$ & $684(12.1)$ & 0.78 \\
\hline Diabetes mellitus & $16983(49.2)$ & $7872(48.4)$ & $6184(49.2)$ & $2927(51.6)$ & $<0.001$ \\
\hline Dementia & 4469 (12.9) & $1966(12.1)$ & $1748(13.9)$ & $755(13.3)$ & $<0.001$ \\
\hline COPD & $14801(42.9)$ & $6627(40.7)$ & $5592(44.5)$ & $2582(45.5)$ & $<0.001$ \\
\hline Asthma & $7374(21.4)$ & $3498(21.5)$ & $2732(21.7)$ & $1144(20.2)$ & 0.05 \\
\hline Renal disease & $7573(21.9)$ & $3307(20.3)$ & $2708(21.5)$ & $1558(27.5)$ & $<0.001$ \\
\hline Liver disease & $579(1.7)$ & $255(1.6)$ & $209(1.7)$ & $115(2.0)$ & 0.07 \\
\hline Cancer & $6639(19.2)$ & $3160(19.4)$ & $2425(19.3)$ & $1054(18.6)$ & 0.38 \\
\hline Metastatic cancer & $915(2.7)$ & $428(2.6)$ & $320(2.5)$ & $167(2.9)$ & 0.29 \\
\hline ADG score, median (IQR) & $14(11-16)$ & $14(11-16)$ & $14(11-16)$ & $13(11-16)$ & $<0.001$ \\
\hline Frailty score $(\%) \dagger$ & $9172(26.6)$ & $3986(24.5)$ & $3471(27.6)$ & $1715(30.2)$ & $<0.001$ \\
\hline Specialist $\ddagger$ visit in year before ED visit & $19767(57.3)$ & $9751(59.9)$ & $7196(57.2)$ & $2820(49.7)$ & $<0.001$ \\
\hline ED visit for same in year before ED visit & $5436(15.7)$ & $2430(14.9)$ & $2054(16.3)$ & $952(16.8)$ & $<0.001$ \\
\hline Admission to hospital for same in $2 \mathrm{yr}$ before ED visit & 7464 (21.6) & 3355 (20.6) & $2799(22.3)$ & $1310(23.1)$ & $<0.001$ \\
\hline
\end{tabular}


Table 1 (part 2 of 2): Patient characteristics at index emergency department visit for heart failure, by timing of follow-up care

Total no. of

patients $(\%)^{\star}$

Characteristic

\section{Hospital-level details}

Triage score at the ED (1 is highest acuity)

1 or 2

3

Arrived by ambulance

Time patient presented to the ED

00:00-07:59

08:00-15:59

16:00-23:59

Patient presented to the ED on the weekend

Hospital type

Community

Small

Teaching

\section{Emergency department physician details}

Female

No. of years of practice

$0-5$

6-10

$11-15$

$>15$

Main specialty

3-yr EM

5 -yr EM

FM

Other

Hospital type

Community

Small

Teaching

\section{Family physician details}

Female

No. of years of practice

$$
\begin{aligned}
& 0-5 \\
& 6-10 \\
& 11-15 \\
& >15
\end{aligned}
$$

Main specialty

FM

EM

Remuneration model

$$
\text { CCM/FHG }
$$

FHN

FHO/FHT

$\mathrm{FHO} /$ no FHT

\begin{tabular}{|c|c|c|c|c|}
\hline 13951 (40.4) & $6653(40.9)$ & $5112(40.7)$ & 2186 (38.5) & 0.006 \\
\hline 20568 (59.6) & 9621 (59.1) & 7460 (59.3) & 3487 (61.5) & \\
\hline 11081 (32.1) & $4892(30.1)$ & 4093 (32.6) & 2096 (36.9) & $<0.001$ \\
\hline $5530(16.0)$ & 2580 (15.9) & $2014(16.0)$ & $936(16.5)$ & 0.35 \\
\hline 19241 (55.7) & 9068 (55.7) & 7068 (56.2) & 3105 (54.7) & \\
\hline 9748 (28.2) & $4626(28.4)$ & 3490 (27.8) & $1632(28.8)$ & \\
\hline $8530(24.7)$ & $4123(25.3)$ & $3038(24.2)$ & $1369(24.1)$ & 0.04 \\
\hline 24561 (71.2) & 11592 (71.2) & 8945 (71.2) & 4024 (70.9) & $<0.001$ \\
\hline $2460(7.1)$ & 991 (6.1) & 960 (7.6) & 509 (9.0) & \\
\hline 7498 (21.7) & 3691 (22.7) & 2667 (21.2) & $1140(20.1)$ & \\
\hline $8093(23.4)$ & 3954 (24.3) & 2873 (22.9) & $1266(22.3)$ & 0.001 \\
\hline 8166 (23.7) & $4066(25.0)$ & 2901 (23.1) & 1199 (21.1) & $<0.001$ \\
\hline 7031 (20.4) & $3324(20.4)$ & 2579 (20.5) & 1128 (19.9) & \\
\hline 6235 (18.1) & 2947 (18.1) & 2254 (17.9) & $1034(18.2)$ & \\
\hline $13087(37.9)$ & 5937 (36.5) & 4838 (38.5) & $2312(40.8)$ & \\
\hline $14575(42.2)$ & 6889 (42.3) & $5323(42.3)$ & $2363(41.7)$ & $<0.001$ \\
\hline $4252(12.3)$ & 2181 (13.4) & 1487 (11.8) & $584(10.3)$ & \\
\hline 11930 (34.6) & 5409 (33.2) & 4390 (34.9) & 2131 (37.6) & \\
\hline $3762(10.9)$ & 1795 (11.0) & $1372(10.9)$ & $595(10.5)$ & \\
\hline 24561 (71.2) & 11592 (71.2) & 8945 (71.2) & $4024(70.9)$ & $<0.001$ \\
\hline $2460(7.1)$ & $991(6.1)$ & 960 (7.6) & $509(9.0)$ & \\
\hline 7498 (21.7) & 3691 (22.7) & 2667 (21.2) & $1140(20.1)$ & \\
\hline 7907 (22.9) & 3825 (23.5) & $2827(22.5)$ & $1255(22.1)$ & 0.04 \\
\hline $1330(3.9)$ & 590 (3.6) & $474(3.8)$ & $266(4.7)$ & 0.008 \\
\hline $1915(5.5)$ & $866(5.3)$ & $722(5.7)$ & $327(5.8)$ & \\
\hline $2997(8.7)$ & $1407(8.6)$ & $1087(8.6)$ & 503 (8.9) & \\
\hline 28277 (81.9) & $13411(82.4)$ & $10289(81.8)$ & 4577 (80.7) & \\
\hline 34135 (98.9) & 16197 (99.5) & 12475 (99.2) & $5463(96.3)$ & $<0.001$ \\
\hline $384(1.1)$ & $77(0.5)$ & $97(0.8)$ & $210(3.7)$ & \\
\hline $14622(42.4)$ & 7385 (45.4) & 5141 (40.9) & 2096 (36.9) & $<0.001$ \\
\hline $2445(7.1)$ & $975(6.0)$ & $981(7.8)$ & $489(8.6)$ & \\
\hline 7075 (20.5) & 3184 (19.6) & $2588(20.6)$ & $1303(23.0)$ & \\
\hline 7259 (21.0) & $3298(20.3)$ & 2747 (21.9) & 1214 (21.4) & \\
\hline $3118(9.0)$ & $1432(8.8)$ & $1115(8.9)$ & $571(10.1)$ & \\
\hline
\end{tabular}

FFS

\section{No. (\%) of patients with follow-up care}

$\begin{array}{ccc}\text { At } 1-7 d & \text { At } 8-30 d & \text { No } 30-d \text { care } \\ n=16274 & n=12572 & n=5673\end{array}$

$p$ value

Note: $\mathrm{ADG}=$ adjusted diagnosis group, $\mathrm{CCM}=$ comprehensive care model, $\mathrm{Cl}=$ confidence interval, $\mathrm{CABG}=$ coronary artery bypass graft, $\mathrm{COPD}=$ chronic obstructive pulmonary disease, $\mathrm{ED}=$ emergency department, $\mathrm{EM}=$ emergency medicine, $\mathrm{FFS}=$ fee for service, $\mathrm{FHG}=$ Family Health Group, $\mathrm{FHN}=$ Family Health Network, $\mathrm{FHO}=\mathrm{Family}$ Health Organization, FHT = family health team, FM = family medicine, ICD = implantable cardioverter defibrillator, IQR = interquartile range, $P P M=$ permanent pacemaker.

*Unless specified otherwise.

†Sixty-seven $(0.2 \%)$ patients were missing a frailty score.

$\ddagger$ Specialist is defined as cardiologist or internist. 
over 1 year (hazard ratio [HR] 0.92, 95\% confidence interval $[\mathrm{Cl}]$ 0.87-0.97) and showed a trend to a lower rate of death over 90 days (HR 0.90, 95\% Cl 0.10-1.00) (Table 2). Kaplan-Meier curves for these comparisons are presented in Figures 2 and 3. Compared with matched patients without 30-day follow-up, patients with basic follow-up also had a reduction in the rate of death over 1 year (HR 0.89, 95\% Cl 0.82-0.97) but not over 90 days (HR $0.91,95 \% \mathrm{Cl}$ 0.78-1.06) (Table 2). Kaplan-Meier curves for these comparisons are presented in Appendix 1 (supplementary Figures 1 and 2).

Among matched female patients, there was no difference in mortality by timing of follow-up care. Among male patients, early follow-up versus days 8 to 30 reduced the rate of death by $11 \%$ at 1 year, and both 1-year and 90-day mortality were reduced (by $11 \%$ and $23 \%$, respectively) with 30 -day follow-up versus none (Appendix 1, part e). Among patients without a history of heart failure, early follow-up was associated with an $18 \%$ reduction in the rate of 1-year mortality compared with between days 8 and 30 (Appendix 1, part f). We found no association between basic care and mortality.

\section{Admissions to hospital}

Matched patients with early follow-up had a reduction in the rate of admission to hospital over 1 year (HR 0.92, 95\% Cl 0.87-0.97) and over 90 days (HR $0.87,95 \% \mathrm{Cl}, 0.80-0.94)$ compared with those seen between days 8 and 30. Among patients with basic follow-up, there was no difference in the rate of admission to hospital over 1 year (HR 1.02, 95\% Cl 0.94-1.10) compared with patients without 30-day follow-up care and a trend to an increase in the rate of 90-day admission to hospital (HR 1.14, 95\% Cl 1.00-1.29) (Table 2).

Admissions to hospital over 1 year were reduced by $9 \%$ among female patients who had early follow-up, whereas, among male patients, there was a trend toward increased admissions to hospital with 30-day follow-up care versus none (HR 1.18, 95\% Cl 0.991.41), but this finding was not statistically significant (Appendix 1 , part e). Among patients with no history of heart failure, early follow-up was associated with a $17 \%$ and $12 \%$ reduction in 90-day and 1 year admission to hospital, respectively, versus 8 to 30 day care (Appendix 1, part f). We found no association between basic care and admission to hospital outcomes.

\section{Diagnostic testing, interventions and guideline-directed medical therapy}

The frequency of subsequent testing and interventions was similar between the matched early versus 8 to 30 -day follow-up groups (Appendix 1, part g), whereas there were more echocardiograms, placements of implantable cardioverter-defibrillators and stress testing among patients seen within 30 days compared with matched patients without 30-day follow-up. Compared with patients without 30-day follow-up, patients seen within 7 days had higher adjusted odds (adjusted odds ratio [OR] 1.42, 95\% Cl 1.12-1.79) of filling a prescription for guideline-directed therapy 1 year later, as did patients with follow-up between days 8 and 30 (adjusted OR 1.52, 95\% Cl 1.19-1.94) (Appendix 1, supplementary Figure 3).

\section{Interpretation}

In this population-based study involving patients with heart failure who received emergency care and were discharged, we found that less than half obtained physician follow-up within 1 week of leaving an emergency department. Follow-up within a week was associated with a reduction in subsequent death in the long term and trended to a lower rate of mortality in the short term for cardiovascular outcomes; admissions to hospital for cardiovascular outcomes were reduced for both the short and long term, compared with later care as much as 30 days after discharge. Follow-up within 30 days was associated with $11 \%$ lower rates of 1 -year mortality compared with no 30 -day follow-up and potentially associated with a $14 \%$ increase in the

Table 2: Unadjusted and adjusted outcomes, by timing of follow-up care

\begin{tabular}{|c|c|c|c|c|c|c|c|c|c|c|c|c|c|}
\hline \multirow[b]{3}{*}{ Outcome } & \multirow{3}{*}{$\begin{array}{c}\text { Total no. } \\
(\%) \text { of } \\
\text { patients } \\
n=34519\end{array}$} & \multirow{2}{*}{\multicolumn{4}{|c|}{ No. (\%) of patients (unadjusted outcome) }} & \multicolumn{8}{|c|}{ Adjusted outcome* } \\
\hline & & & & & & \multicolumn{4}{|c|}{ Follow-up care within $7 \mathrm{~d} \mathrm{v} .8-30 \mathrm{~d}$} & \multicolumn{4}{|c|}{$\begin{array}{l}\text { Follow-up care within } 30 \mathrm{~d} \text { v. no } 30 \text {-d } \\
\text { follow-up }\end{array}$} \\
\hline & & $\begin{array}{l}\text { Within } 7 \mathrm{~d} \\
n=16274\end{array}$ & $\begin{array}{l}\text { At } 8-30 \mathrm{~d} \\
n=12572\end{array}$ & $\begin{array}{c}\text { None } \\
n=5673\end{array}$ & $\begin{array}{c}p \\
\text { valuet }\end{array}$ & $\begin{array}{l}\text { AER } \\
(\%)\end{array}$ & $\operatorname{HR}(95 \% \mathrm{CI})$ & $\begin{array}{c}\text { ARR, } \\
\%\end{array}$ & NNT & $\begin{array}{l}\text { AER } \\
(\%)\end{array}$ & HR $(95 \% \mathrm{CI})$ & $\begin{array}{c}\text { ARR, } \\
\%\end{array}$ & NNT \\
\hline $\begin{array}{l}\text { Mortality, } \\
1-y r\end{array}$ & $8129(23.5)$ & $3533(21.7)$ & $\begin{array}{c}2982 \\
(23.7)\end{array}$ & $1614(28.5)$ & $<0.001$ & $\begin{array}{l}19.6 \\
(21.2)\end{array}$ & $0.92(0.87-0.97)$ & 1.6 & 63 & $\begin{array}{l}20.7 \\
(22.9)\end{array}$ & $0.89(0.82-0.97)$ & 2.2 & 45 \\
\hline $\begin{array}{l}\text { Mortality, } \\
\text { 90-d }\end{array}$ & $3213(9.3)$ & $1418(8.7)$ & $1049(8.3)$ & $746(13.2)$ & $<0.001$ & $\begin{array}{c}5.1 \\
(5.7)\end{array}$ & $0.90(0.81-1.00)$ & 0.6 & 167 & $\begin{array}{c}5.9 \\
(6.5)\end{array}$ & $0.91(0.78-1.06)$ & NS & NS \\
\hline $\begin{array}{l}\text { Admitted } \\
\text { to hospital } \\
\text { within } 1 \mathrm{yr}\end{array}$ & $\begin{array}{l}11180 \\
(32.4)\end{array}$ & $5324(32.7)$ & $\begin{array}{c}3893 \\
(31.0)\end{array}$ & $1963(34.6)$ & $<0.001$ & $\begin{array}{c}26.6 \\
(28.1)\end{array}$ & $0.92(0.87-0.97)$ & 1.5 & 67 & $\begin{array}{c}27.3 \\
(26.9)\end{array}$ & $1.02(0.94-1.10)$ & NS & NS \\
\hline $\begin{array}{l}\text { Admitted } \\
\text { to hospital } \\
\text { within } \\
90 \mathrm{~d}\end{array}$ & $6139(17.8)$ & $3043(18.7)$ & $\begin{array}{r}1949 \\
(15.5)\end{array}$ & $1147(20.2)$ & $<0.001$ & $\begin{array}{c}10.1 \\
(11.4)\end{array}$ & $0.87(0.80-0.94)$ & 1.3 & 77 & $\begin{array}{l}10.7 \\
(9.5)\end{array}$ & $1.14(1.00-1.29)$ & - & - \\
\hline
\end{tabular}




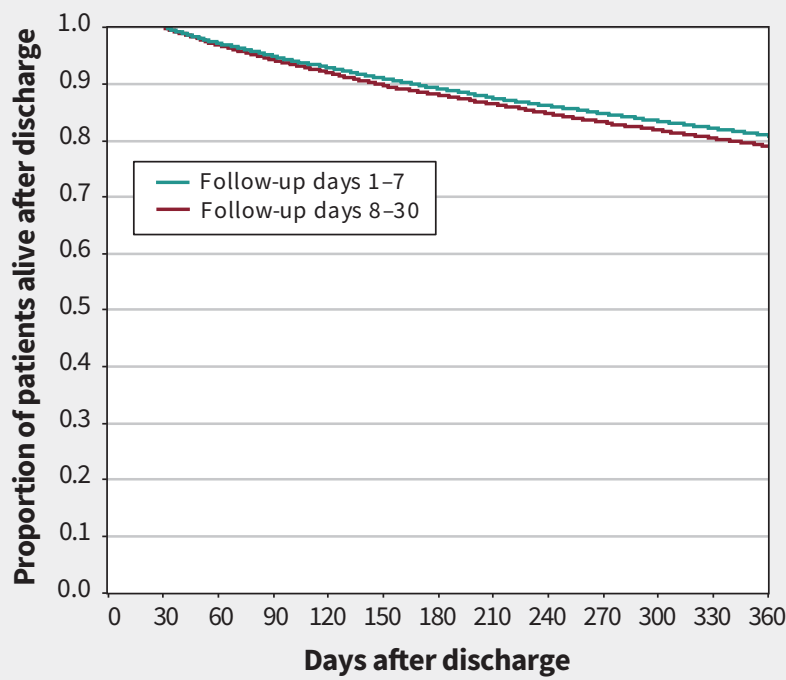

Figure 2: Kaplan-Meier curve for mortality after discharge from the emergency department $(1 \mathrm{yr})$ in matched patients with heart failure who had follow-up care between days 1 and 7 versus 8 and 30 using propensity score-matched groups. Landmark at 30 days.

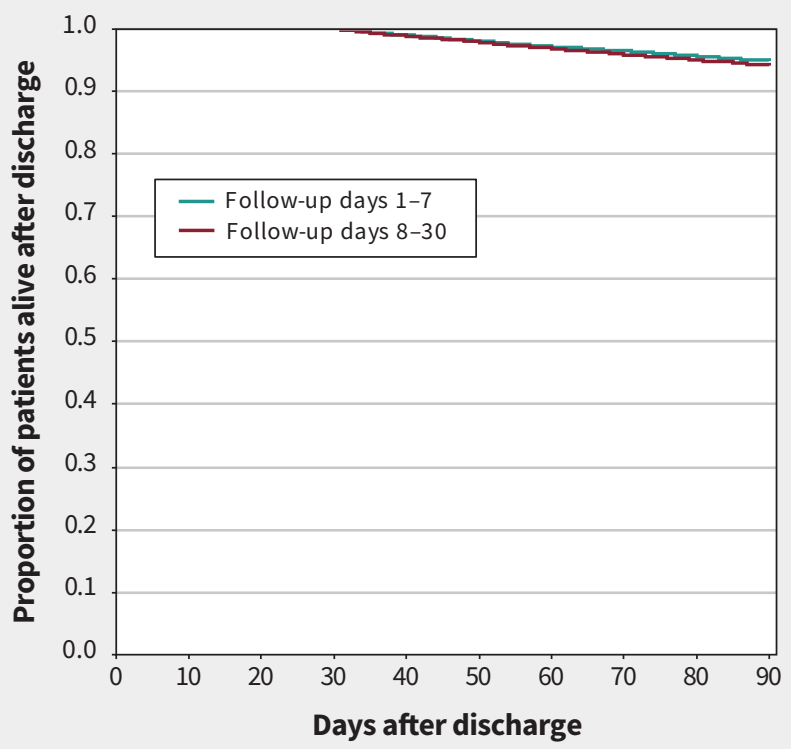

Figure 3: Kaplan-Meier curve for mortality after discharge from the emergency department $(90 \mathrm{~d})$ in matched patients with heart failure who had follow-up care between days 1 and 7 versus 8 and 30, using propensity score-matched groups. Landmark at 30 days.

risk of subsequent admission to hospital within 90 days. These results suggest that follow-up within 7 days is optimal to keep more patients alive and out of hospital. If 7-day follow-up is viewed as a medication, the number needed to treat (NNT) is 63, which is an acceptable value. In patients with incident heart failure, the NNT was 40. For comparison, the NNT with daily $\beta$-blocker therapy to prevent 1 death at 7 months is $38 .{ }^{43}$

At present, the optimal time for follow-up after discharge from an emergency department following an exacerbation of heart failure is unknown. Guidelines based on expert opinion suggest follow-up with a specialist within 14 days. ${ }^{13,31} \mathrm{~A}$ prospective study involving 410 patients from 8 emergency departments in Quebec did not find a statistically significant difference in the composite outcome of death, admission to hospital or return emergency visit between 14-day follow-up and no such followup; however, a reduction was found with 4- and 6-week followup. ${ }^{10}$ The reason for the difference in findings compared with our study is likely sample size. A larger retrospective study at 93 emergency departments in Alberta found a reduction in the adjusted hazards of death and admission to hospital at 6 months if patients were seen within 30 days. ${ }^{11} \mathrm{~A}$ study in the United States involving patients with heart failure who were 65 years or older and admitted to hospital found that patients discharged from hospitals who were in the highest quartile of 7-day followup rates had lower 30 -day readmission rates. ${ }^{12}$ Our findings show further evidence of 7-day follow-up in a different health care system, where there are no penalties for higher 30-day readmissions, and at the patient level.

Unlike patients admitted to hospital, patients discharged from the emergency department do not receive daily assessment and investigations by physicians and nurses. These patients are left to arrange their own subsequent care. Although many are safe to discharge from the emergency department, ${ }^{29,44}$ our findings show that provision of physician follow-up within 1 week occurs in less than half of such discharges in Ontario. The rate may be even lower in other regions, such as Quebec (about 20\%). ${ }^{10}$

Potential systems-level solutions include care by nurse practitioners, physician assistants and transitional care clinics. ${ }^{45}$ Telemedicine is an option of increasing interest for follow-up of patients in remote areas. Health insurance is one of the most important predictors of obtaining follow-up care; ${ }^{46,47}$ therefore, in the US, outcomes will likely be affected by the future of the Affordable Care Act. ${ }^{48}$

Based on observational data from patients with heart failure who were admitted to hospital, ${ }^{12}$ the American College of Cardiology Foundation/American Heart Association Task Force recommended that all patients with heart failure who have been admitted to hospital should have a follow-up appointment scheduled before discharge. ${ }^{2} \mathrm{~A}$ study involving patients who were admitted to hospital and who received scheduled followup appointments between 2009 and 2012 found an improvement: $51 \%$ to $65 \% .{ }^{49}$ Given our findings, we argue that scheduled follow-up appointments for patients with heart failure in the emergency department should be prioritized in the same manner. Providing such an appointment before the patient leaves the emergency department is one of the most efficient ways to ensure timely follow-up. ${ }^{50}$ The major barrier is that most patients in the emergency department are seen when outpatient offices are not available for real-time communication; 
however, managed care consortiums with linked hospital and outpatient office electronic health records (e.g., Veterans Health Administration, Kaiser-Permanente in the US) have the capability to provide scheduled follow-up appointments outside of business hours. ${ }^{51}$

We found a potential increased risk of 90-day admission to hospital associated with basic follow-up versus no 30-day care. Although of borderline statistical significance, this finding could be secondary to early identification of disease instability, which may lead to referral for hospital admission. In turn, admission to hospital could lower subsequent mortality, resulting in a lower rate of 1-year mortality in the basic follow-up group compared with the no 30-day follow-up group. For patients seen more than a month after discharge, there may be some provider and patient inertia around starting investigations, given that the emergency visit was over a month earlier and other management priorities may have arisen to supersede the heart failure.

We found that more tests and interventions were performed in patients seen within 30 days, which may contribute to lower mortality and admissions to hospital. In older patients who were not taking guideline-directed medical therapy, those with early follow-up were $42 \%$ more likely to be taking this therapy 1 year later. This result suggests another route to improved mortality. Because the risk reduction conferred by these medications is cumulative over time, the widening of the Kaplan-Meier curves over time is consistent with this hypothesis. Increased access to providers (whether a physician or specialized nursing care) could also support educational efforts on important self-care interventions by patients with heart failure, including nonpharmacologic modalities.

\section{Limitations}

We used propensity score methods to match groups on multiple factors; however, propensity scores cannot account for unmeasured covariates. The ethical issues surrounding random assignment to early versus later follow-up may preclude a randomized trial on this topic. Our study was conducted in Ontario, which has universal health care coverage, and our findings may not be generalizable to patients without health insurance, nor to those without a family physician; however, timely access to care has been shown to be worse in Canada than in other developed countries. ${ }^{52}$ We did not include admissions to hospital for other reasons, where heart failure may have been a secondary diagnosis. This may have resulted in an underestimation of the number of subsequent admissions to hospital where heart failure played a role. We did not have access to ejection fraction, and strong evidence for the reduction in mortality and admissions to hospital by guideline-directed medical therapy exists only for patients with reduced ejection fraction. ${ }^{2}$ Our findings may be an underestimation of the association between timely follow-up and outcomes in patients with reduced ejection fraction.

The effect of early follow-up might be expected to be greatest in the initial period after discharge. However, the KaplanMeier curves in our study did not separate early, which may be due to the landmark analysis starting at day 30; we may have underestimated the early effect. In addition to systems factors, patient adherence to follow-up may play a role in outcomes. However, because more than $90 \%$ of patients discharged from the emergency department with a cardiovascular ambulatory sensitive-care condition have documented follow-up instructions, ${ }^{53}$ and follow-up rates vary little between diseases of varying severity, ${ }^{54,55}$ we believe patient adherence played a smaller role.

\section{Conclusion}

We found that among patients who received emergency care for heart failure, obtaining follow-up within 1 week of discharge from the emergency department may be associated with a reduced rate of subsequent admission to hospital and death. This study provides evidence to support the timing of follow-up care for an expanding population of patients. Obtaining early follow-up for all of these patients will require a transition in systematic care between emergency and longitudinal care, via collaboration between administrators, researchers, clinicians and information technology specialists.

\section{References}

1. Singer AJ, Emerman C, Char DM, et al. Bronchodilator therapy in acute decompensated heart failure patients without a history of chronic obstructive pulmonary disease. Ann Emerg Med 2008;51:25-34.

2. Writing committee members; Yancy CW, Jessup M, Bozkurt B, et al.; American College of Cardiology Foundation/American Heart Association Task Force on Practice Guidelines. 2013 ACCF/AHA guideline for the management of heart failure: a report of the American College of Cardiology Foundation/American Heart Association Task Force on practice guidelines. Circulation 2013; 128:e240-327.

3. Hugli O, Braun JE, Kim S, et al. United States emergency department visits for acute decompensated heart failure, 1992 to 2001. Am J Cardiol 2005;96:1537-42.

4. Lee DS, Schull MJ, Alter DA, et al. Early deaths in patients with heart failure discharged from the emergency department: a population-based analysis. Circ Heart Fail 2010;3:228-35.

5. Ezekowitz JA, Bakal JA, Kaul P, et al. Acute heart failure in the emergency department: short and long-term outcomes of elderly patients with heart failure. Eur J Heart Fail 2008;10:308-14.

6. 2016 report on the health of Canadians: the burden of heart failure. Ottawa: Heart and Stroke Canada; 2017. Available: www.heartandstroke.ca/-/media/ pdf-files/canada/2017-heart-month/heartandstroke-reportonhealth-2016.ash x?la=en\&hash=0478377DB7CF08A281E0D94B22BED6CD093C76DB (accessed 2018 Aug. 15)

7. Heidenreich PA, Albert NM, Allen LA, et al.; American Heart Association Advocacy Coordinating Committee; Council on Arteriosclerosis, Thrombosis and Vascular Biology; Council on Cardiovascular Radiology and Intervention; Council on Clinical Cardiology; Council on Epidemiology and Prevention; Stroke Council. Forecasting the impact of heart failure in the United States: a policy statement from the American Heart Association. Circ Heart Fail 2013; 6:606-19.

8. Tran DT, Ohinmaa A, Thanh NX, et al. The current and future financial burden of hospital admissions for heart failure in Canada: a cost analysis. CMAJ Open 2016;4:E365-70.

9. Patients first: action plan for health care. Toronto: Ontario Ministry of Health and Long-Term Care; 2017. Available: www.health.gov.on.ca/en/ms/ecfa/ healthy_change/ (accessed 2018 Mar. 14).

10. Feldman DE, Huynh T, Lauriers JD, et al. Access to heart failure care post emergency department visit: Do we meet established benchmarks and does it matter? Am Heart J 2013;165:725-32. 
11. Sidhu RS, Youngson E, McAlister FA. Physician continuity improves outcomes for heart failure patients treated and released from the emergency department. JACC Heart Fail 2014;2:368-76.

12. Hernandez AF, Greiner MA, Fonarow GC, et al. Relationship between early physician follow-up and 30-day readmission among Medicare beneficiaries hospitalized for heart failure. JAMA 2010;303:1716-22.

13. Howlett JG, Chan M, Ezekowitz JA, et al. The Canadian Cardiovascular Society Heart Failure companion: bridging guidelines to your practice. Can J Cardiol 2016;32:296-310.

14. Arnold JM, Liu P, Demers C, et al.; Canadian Cardiovascular Society. Canadian Cardiovascular Society consensus conference recommendations on heart failure 2006: diagnosis and management. Can J Cardiol 2006;22: 23-45.

15. CONSENSUS Trial Study Group. Effects of enalapril on mortality in severe congestive heart failure. Results of the Cooperative North Scandinavian Enalapril Survival Study (CONSENSUS). N Engl J Med 1987;316:1429-35.

16. Effect of metoprolol $\mathrm{CR} / \mathrm{XL}$ in chronic heart failure: Metoprolol $\mathrm{CR} / \mathrm{XL}$ Randomised Intervention Trial in Congestive Heart Failure (MERIT-HF). Lancet 1999;353:2001-7.

17. Flather MD, Yusuf S, Køber L, et al. Long-term ACE-inhibitor therapy in patients with heart failure or left-ventricular dysfunction: a systematic overview of data from individual patients. ACE-Inhibitor Myocardial Infarction Collaborative Group. Lancet 2000;355:1575-81.

18. Garg R, Yusuf S. Overview of randomized trials of angiotensin-converting enzyme inhibitors on mortality and morbidity in patients with heart failure. Collaborative Group on ACE Inhibitor Trials. JAMA 1995;273:1450-6.

19. Ezekowitz JA, van Walraven C, McAlister FA, et al. Impact of specialist followup in outpatients with congestive heart failure. CMAJ 2005;172:189-94.

20. Cho DD, Austin PC, Atzema CL. Management of discharged emergency department patients with a primary diagnosis of hypertension: a multicentre study. CJEM 2015;17:523-31.

21. National Ambulatory Care Reporting System Metadata (NACRS). Ottawa: Canadian Institute for Health Information. Available: www.cihi.ca/en/types-of-care/ hospital-care/emergency-and-ambulatory-care/nacrs-metadata (accessed 2016 June 2)

22. du Plessis V, Beshiri R, Bollman RD, et al. Definitions of rural. In: Rural and Small Town Canada Analysis Bulletin 2001. Cat no 21-006-XIE. Ottawa: Statistics Canada, Agricultural Division.

23. Beveridge $\mathrm{R}$, Clarke $\mathrm{B}$, Janes $\mathrm{L}$, et al. Implementation guidelines for the Canadian Emergency Department Triage \& Acuity Scale (CTAS). Ottawa: Canadian Association of Emergency Physicians (CAEP); 1998. Available: http://caepca/ resources/ctas/implementation-guidelines (accessed 2017 May 25).

24. Williams JI, Young W. Appendix I: A summary of studies on the quality of health care administrative databases in Canada. In: Goel V, Williams JI, Anderson GM, et al., editors. The ICES Practice Atlas: Patterns of health care in Ontario. 2nd ed. Ottawa: Canadian Medical Association; 1996:339-45. Available: www.ices.on.ca/Publications/Atlases-and-Reports/1996/Patterns-of -health-care-2nd-ed (accessed 2012 Sept. 6).

25. Lee DS, Stukel TA, Austin PC, et al. Improved outcomes with early collaborative care of ambulatory heart failure patients discharged from the emergency department. Circulation 2010;122:1806-14.

26. Beyersmann J, Gastmeier P, Wolkewitz M, et al. An easy mathematical proof showed that time-dependent bias inevitably leads to biased effect estimation. J Clin Epidemiol 2008;61:1216-21.

27. Rosenbaum PR, Rubin DB. The central role of the propensity score in observational studies for causal effects. Biometrika 1983;70:41-55. doi: 10.2307/ 2335942.

28. Rosenbaum P, Rubin D. Constructing a control group using multivariate matched sampling methods that incorporate the propensity score. Am Stat 1985;39:33-8. doi: 10.2307/2683903.
29. Hsieh M, Auble TE, Yealy DM. Validation of the acute heart failure index. Ann Emerg Med 2008;51:37-44.

30. Lee DS, Stitt A, Austin PC, et al. Prediction of heart failure mortality in emergent care: a cohort study. Ann Intern Med 2012;156:767-75, W-261, W262.

31. Ross H, Howlett J, Arnold JM, et al.; Canadian Cardiovascular Society Access to Care Working Group. Treating the right patient at the right time: access to heart failure care. Can J Cardiol 2006;22:749-54.

32. Gershon AS, Wang C, Guan J, et al. Identifying patients with physician-diagnosed asthma in health administrative databases. Can Respir J 2009;16:183-8.

33. Gershon AS, Wang C, Guan J, et al. Identifying individuals with physcian diagnosed COPD in health administrative databases. COPD 2009;6:388-94.

34. Hall R, Mondor L, Porter J, et al. Accuracy of administrative data for the coding of acute stroke and TIAs. Can J Neurol Sci 2016;43:765-73.

35. Hux JE, Ivis F, Flintoft V, et al. Diabetes in Ontario: determination of prevalence and incidence using a validated administrative data algorithm. Diabetes Care 2002;25:512-6

36. Lee DS, Donovan L, Austin PC, et al. Comparison of coding of heart failure and comorbidities in administrative and clinical data for use in outcomes research. Med Care 2005;43:182-8.

37. Schultz SE, Rothwell DM, Chen Z, et al. Identifying cases of congestive heart failure from administrative data: a validation study using primary care patient records. Chronic Dis Inj Can 2013;33:160-6.

38. Tu K, Campbell NR, Chen ZL, et al. Accuracy of administrative databases in identifying patients with hypertension. Open Med 2007;1:e18-26.

39. Austin PC. Optimal caliper widths for propensity-score matching when estimating differences in means and differences in proportions in observational studies. Pharm Stat 2011;10:150-61.

40. Austin PC. A comparison of 12 algorithms for matching on the propensity score. Stat Med 2014;33:1057-69.

41. Austin PC. Balance diagnostics for comparing the distribution of baseline covariates between treatment groups in propensity-score matched samples. Stat Med 2009;28:3083-107.

42. Austin PC. The performance of different propensity score methods for estimating marginal hazard ratios. Stat Med 2013;32:2837-49.

43. Lechat $P, P$ acker $M$, Chalon $S$, et al. Clinical effects of $\beta$-adrenergic blockade in chronic heart failure: a meta-analysis of double-blind, placebo-controlled, randomized trials. Circulation 1998;98:1184-91.

44. Lee DS, Lee JS, Schull MJ, et al. Design and rationale for the Acute Congestive Heart Failure Urgent Care Evaluation: The ACUTE Study. Am Heart J 2016; 181:60-5.

45. Dunbar-Yaffe R, Stitt A, Lee JJ, et al. Assessing risk and preventing 30-day readmissions in decompensated heart failure: Opportunity to intervene? Curr Heart Fail Rep 2015;12:309-17.

46. Mouton CP, Beaudouin R, Troutman A, et al. Barriers to follow-up of hypertensive patients. J Health Care Poor Underserved 2001;12:290-301.

47. Qureshi R, Asha SE, Zahra M, et al. Factors associated with failure to follow up with a general practitioner after discharge from the emergency department. Emerg Med Australas 2012;24:604-9.

48. Blumenthal D, Abrams M, Nuzum R. The affordable care act at 5 years. N Engl J Med 2015;373:1580

49. DeVore AD, Cox M, Eapen ZJ, et al. Temporal trends and variation in early scheduled follow-up after a hospitalization for heart failure: findings from Get With The Guidelines-Heart Failure. Circ Heart Fail 2016;9:e002344.

50. Atzema CL, Maclagan LC. The transition of care between emergency department and primary care: a scoping study. Acad Emerg Med 2017;24 201-15. 
51. Watkins LM, Patrician PA. Handoff communication from the emergency department to primary care. Adv Emerg Nurs J 2014;36:44-51.

52. Reducing care fragmentation: a toolkit for coordinating care. Seattle: Improving Chronic Illness Care; 2011. Available: www.improvingchroniccare. org/downloads/care_coordination_toolkit.pdf (accessed 2018 Oct. 30).

53. Atzema CL, Austin PC, Chong AS, et al. The long-term use of warfarin among atrial fibrillation patients discharged from an emergency department with a warfarin prescription. Ann Emerg Med 2015;66:347-54.e2.
54. Schull MJ, Vermeulen M, Stukel T, et al. Follow-up and shared care following discharge from the emergency department for exacerbations of chronic disease. CJEM 2013;15(Suppl 1):S16.

55. Atzema CL, Yu B, Ivers NM, et al. Predictors of obtaining follow-up care in the province of Ontario, Canada, following a new diagnosis of atrial fibrillation, heart failure, and hypertension in the emergency department. CJEM 2018;20:377-91.

\section{Competing interests: None declared.}

This article has been peer reviewed.

Affiliations: ICES (Atzema, Austin, Yu, Schull, Jackevicius, Ivers, Rochon, Lee); Divisions of Emergency Medicine (Atzema, Schull) and Cardiology (Lee), Departments of Medicine and Family Medicine (Ivers), and the Institute for Health Policy, Management and Evaluation (Atzema, Austin, Schull, Jackevicius, Ivers, Rochon, Lee), University of Toronto; Sunnybrook Health Sciences Centre (Atzema, Schull, Austin); Women's College Hospital (Ivers, Rochon); University Health Network (Jackevicius, Lee); Toronto, Ont.; Western University of Health Sciences (Jackevicius), Pomona, Calif.; Veteran's Affairs Greater Los Angeles Healthcare System (Jackevicius), Los Angeles, Calif.

Contributors: Clare Atzema acquired the data and drafted the manuscript. Clare Atzema, Peter Austin and Bing Yu analyzed and interpreted the data, and conducted the statistical analysis. All of the authors contributed to the conception and design of the work, revised it critically for important intellectual content, gave final approval of the version to be published and agreed to be accountable for all aspects of the work.

Funding: This project was supported by a grant from the Canadian Institutes of Health Research (CIHR) (142415). Clare Atzema is supported by a Mid-Career Investigator Award from the Heart and Stroke Foundation of Ontario (HSFO), ICES, the Practice Plan of the Department of Emergency Services at Sunnybrook Health Sciences Centre and the Sunnybrook Research Institute. Peter Austin is supported by a Mid-Career Investigator Award from the HSFO. Michael Schull is supported by an Applied Chair in Health Services and Policy Research from CIHR. Noah Ivers is supported by a New Investigator Award from CIHR. Paula Rochon holds the Retired Teachers of Ontario/ ERO Chair in Geriatric Medicine. Douglas Lee is supported by the Ted Rogers Chair in Heart Function Outcomes and a Mid-Career Investigator Award from the HSFO.

Data sharing: The data set from this study is held securely in coded form at ICES. Although data-sharing agreements prohibit ICES from making the data set publicly available, access may be granted to those who meet prespecified criteria for confidential access, available at www.ices.on.ca/DAS. The full data set creation plan and underlying analytic code are available from the authors upon request, with the understanding that the programs may rely upon coding templates or macros that are unique to ICES.

Disclaimer: The Heart and Stroke Foundation of Ontario had no involvement in the design or conduct of the study, data management or analysis, or manuscript preparation, review or authorization for submission. This study was supported by ICES, which is funded by an annual grant from the Ontario Ministry of Health and Long-Term Care (MOHLTC). The opinions, results and conclusions reported in this paper are those of the authors and are independent from the funding sources. No endorsement by ICES or the Ontario MOHLTC is intended or should be inferred.

Accepted: Oct. 30, 2018

Correspondence to: Clare Atzema, clare. atzema@ices.on.ca 